\title{
The Effect of Public Transportation on the Sustainability of Lebanon’s Tourism Industry
}

\author{
Said Ladki, Racha Bazzi, Rana Hallal \\ Lebanese American University, Beirut, Lebanon
}

\begin{abstract}
The purpose of this study is to investigate the effects of Lebanese public transport on the sustainability of internal and inbound tourism. The study dependent variables were the three research hypotheses: (1) safety of public transport; (2) reliability of public transport; and (3) fixed pricing. The results of the multivariate analysis test showed strong significance for the need to avoid stress and use the hop-on hop-off bus $(F=7.47, p=0.001)$, the need for a reliable bus $(F=8.16, p=0.01)$ especially for those living far from their work/school, and the need to save time on the road using the bus $(F=5.10, p=0.012)$. Also, the study shows that those living far from their work/school $(F=5.15, p=0.01)$ would prefer a monthly payment pass.
\end{abstract}

Keywords: transportation, tourism, traffic, safety, hop-on hop-off buses

\section{Introduction}

The purpose of this study is to investigate the effects of Lebanese public transport on the sustainability of internal and inbound tourism.

Public transportation is an important component of the tourism sector. It is well documented that reliable transportation system contributes to economic growth (Otego, 2008). The transport system can easily boost or challenge the volume of inbound tourism in countries whose economies are tourism dependent. Manohar and Kumar (2012) defined transportation as "an essential part of human activity which forms the bases of all socio-economic interaction... Indeed, no two locations will interact effectively without a viable means of movement”.

Lebanon is a developing country which is plagued by poorly maintained roads, eternal slow moving traffic, congested highways, unscheduled run down overcrowded buses, inadequate fleets, trucks using inner city roads, double parallel parking, etc.. All have created an ailing transport system which is negatively affecting tourism, the nation's economy, and the population quality of life. Transportation in Lebanon has become a burden rather than a service. Berro (as cited in Khraiche, 2011), the president of the Lebanese Consumers Association, reported that, "We can't build a modern economy without efficient public services, primarily an organized transportation system”. Further, Manohar and Kumar (2012, pp. 94-107) argued that poor transport system can result in "exponential growth of personalized mode of transport leading to enormous problems of traffic congestion, and pollution”.

Said Ladki, Interim Dean of Business School, Lebanese American University. Email: sladki@lau.edu.lb.

Racha Bazzi, MBA student, Lebanese American University.

Rana Hallal, MBA student, Lebanese American University. 
Lebanon is a small nation with a population of approximately four million people, and a land area of 4,036 sq. mile. The population to car ratio is one vehicle for every two individuals (Obeid \& Diab, 2012). In contrast, neighboring Turkey has a population of 74.9 million people and a ratio of one car for every seven people (Obeid \& Diab, 2012). Similarly, Egypt has a population of 83.95 million people and a ratio of one car for every 14 people (BEFORWARD, 2014). In Lebanon, the absence of a reliable public transport system led to increased car ownership. Having too many cars in a highly populated and geographically small area has created numerous problems. In fact, as the mayor of Bogota said: "A developed country is not the place where the poor have cars. It is where the rich use public transportation". The lack of investment in Lebanese transportation system has resulted in an inefficient transportation system that is hindering tourism advancement. Therefore, this paper explores the possibility of introducing hop-on hop-off deluxe bus in the Lebanese market targeting all the population regardless of their social class.

The bus service hop-on hop-off is a type of tourist deluxe bus which follows pre-set routes with multiple pre-set stops. The system allows passengers unlimited travels with the option to hop-off at one stop and hop-on at another for the same fare.

\section{Literature Review}

Mammadov (2012) defined transportation as the voluntary movement of people from one location to another. Sorupia (2005) viewed transportation as an enabler system which transits people from their residences to their touristic destinations. According to a study by Brida and Risso (2010), advancement in transportation infrastructure and telecommunication systems is crucial to improve the tourism sector. Malhado and Rothfuss (2013) confirmed that improving public transportation modes and infrastructure results in an increasing number of tourists, better quality of life, less air pollution, and less congestion. The improvements in transport infrastructure give people an opportunity to adapt to different norms of travel behavior (Malhado \& Rothfuss, 2013). Instructional instruments and good management of public transport system are determinants to successful destination positioning (Mammadov, 2012).

Vietnam's government set a goal of increasing growth rate through enhancing its tourism position on the touristic map and increasing its domestic and international visitors from $10 \%$ to $20 \%$ annually. To attain this goal and develop sustainable tourism, various sectors were encouraged to invest in enhancing tourism infrastructure (Truong, 2013). The flourishing of tourism in the Chinese Lijang province forced the government to invest in building transportation infrastructure and to assort transportation initiatives such as horseback riding, cabs, bicycle leasing (Wu, Xu, \& Eaglen, 2011), whereas in Lagos, Nigeria, after improving the public transport through implementing bus rapid transport (BRT) system, the average fares decreased by $30 \%$ despite an increase of $100 \%$ in gasoline cost. "Commuters have also cut their transit time by 40 percent, and reduced the average waiting time by 35 percent. Time and money spent by poor households on travel was reduced from 90 minutes and 150 Naira in 2003, to 23 minutes and 100 Naira by June 2009” (The World Bank, 2014). Unfortunately, for many developing countries, poor transportation networks are becoming the norm. Maurice Obeid (2012), a management consultant with McKinsey \& Company in New York, confirmed that "If there is ever a cause that unites the Lebanese, it must be transportation... it is a public necessity". 
Otego (2008) reported that development in the transportation system has revolutionized the tourism industry. Qabbani (as cited in Azakir, 2014) stated that, "This is not the first time that we considered a plan for improving public transportation, but traffic problems and difficulty of circulation in Beirut and its outskirts have exacerbated to a point beyond anyone’s tolerance”. Unfortunately, Lebanon has no comprehensive transport strategy and is failing to invest in its transportation system. The Lebanese public transport system is privatized and provided by old and poorly maintained vehicles. The lack of transport codes and enforcement measures is compounding the problems. The absence of modern transport codes and systems is compelling the people of Lebanon to depend on private auto ownership. In fact, Lebanon's auto ownership rate is one of the highest in the world (E. M. Choueiri, G. M. Choueiri, \& B. M. Choueiri, 2012).

Countries that introduced hop-on hop-off buses have served not only local population but also the inbound tourist. Lumsdon and Downward (2004, pp. 415-420) stated that:

A one stop tour bus is likely to generate fewer spending than a series of stops along an established route. Passengers of the hop-on hop-off buses can access the bus from the car parks along the established routes which is a clear move to encourage people to consume while in the interchange.

There are three issues that are challenging the Lebanese public transportation system.

\section{Safety of Public Transport}

Hypothesis 1: There is a direct relationship between road safety and the use of public transport.

Road safety is the result of multiple factors including: community codes, innovative engineering, international standards, compliance, safe and trusted auto repair, defensive driving, etc. (Choueiri et al., 2012).

At best, Lebanon roads' safety records are described as hazardous and not driver friendly. According to the Lebanese Crime and Safety Report issued by the Bureau of Diplomatic Security (2014) in the United States, the report continues to advise U.S. citizens to avoid all travel to Lebanon because of security and safety concerns. From the safety concerns arises the issue of road safety:

The roadways operate unconventionally, with drivers often maneuver aggressively and pay little regard to traffic lights and stop signs, erratic traffic pattern, poorly marked merges, inconsistent police enforcement, high rates of speed, and heavy periods of traffic congestion are most noticeable during the morning and afternoon rush hours and during times of inclement weather. (Bureau of Diplomatic Security, 2014)

According to the Lebanese Internal Security Forces (ISF) report (as cited in Whiting, 2013), there were 2,215 crashes, 3,084 injuries, and 237 deaths which took place during the first six months of 2012. In 2014, 4,907 accidents, 6,463 injuries, and 657 fatalities were reported and about $16 \%$ of these accidents were committed by youth who are below the legal driving age. According to the World Health Organization (2004), by the year 2020, road traffic injuries will be the third leading cause of disability. International Road Federation (2015) statistics showed that five countries in the Middle East (Iran, Iraq, Libya, Oman, and Yemen) are in the top road accidents fatalities rate in the world.

In Lebanon, the absence of traffic lights has resulted in serious traffic and auto accidents. Traffic police seldom respond to auto accidents. Accident reports and inquiries are usually not conducted by the authorities. Insurance companies have private accident investigators who respond to accidents and may be biased toward the insured party. Accident victims usually solve auto accident related disputes without the involvement of safety authorities. If material damage or personal injuries take place, authorities always get engaged (Bureau of Diplomatic Security, 2014). Road safety in Lebanon is also challenged when roads are blocked to provide space 
for those who are demonstrating for a cause. If demonstrators choose to become violent, they set used tires on fire and they block traffic for hours. Convenience, comfort, and safety of transportation in Lebanon are far below acceptable international standards.

Lebanon inbound tourists are extremely cautious when using public transport. Since Lebanon does not have trains, metros, or somewhat acceptable bus transport system, travelers call for taxi service or utilize a car for hire service rather than flagging down passing cabs. "Since attitudes toward travel affect the daily mode choice behavior, the choice of public transportation could in turn affect attitudes in the longer term” (Popuri, Proussaloglou, Ayvalik, Koppelman, \& Lee, 2011).

\section{Reliability of Public Transport}

Hypothesis 2: There is a direct relationship between the reliability of public transport and the increase in the usage of public transport.

Reliability relates to travel time uncertainty from the start to the end of a person's journey. For a public transport journey, reliability means on-time departure and arrival regardless of road conditions and traffic delays. If transport lacks reliability, passengers arrive at the destination at undesirable time (Vincent, 2008).

A destination's location plays a fundamental role in its attractiveness. For inbound tourists, it is crucial to arrive at the destination on time by an efficient and effective mode of transportation. Transportation delays drive tourists away. Inbound and internal tourists need to trust the transportation networks in order to enjoy their journey or get to their daily workplace on time. Li and Lo (2005) reported that a passenger is in need of the following: "The need of reliable and stress-free commute, need for privacy and comfort, the complexity of trip-making behavior, tolerance to waiting and walking, general attitude toward public transportation, and finally, the perceived safety of the travel environment”.

In order for a passenger to use a certain mode of transportation, he/she needs to trust that their choice of transportation is reliable. The way vacationers or commuters perceive transit has a major influence on the choice of method of transport (Li \& Lo, 2005).

\section{Fixed Pricing}

Hypothesis 3: There is a positive relationship between fixed pricing and the increase in the usage of public transport.

Currently, there is no fixed price for public transportation in Lebanon. The cost of any transportation service is generally negotiated by the drivers, cab companies, and the passengers. The absence of taxi meters and tariffs is frustrating cab companies and passengers. Transportation fees are always negotiated. Foreign tourists are usually not provided with information detailing the costs of ground travel in and around Lebanon. Absence of such information has led unscrupulous cab drivers to overcharge tourists.

The Lebanese government is not proactive in its desire to install taxi meters, or come up with agreed upon transport fees. Downward and Lumsdon (2004) explained that consumers use privately-owned bus for: "price, convenience, flexibility, comfort, environmental awareness, etc. Affordability was the most cited reason. This was strongly related to the concept of value for money, rather than simply price”. Internal and inbound tourists need to feel at ease when using ground transport. Tourists should not be exploited or be overcharged when being transported. To alleviate this issue, cab meters and public buses need to fix their prices and display in public. 


\section{Methodology}

\section{Sample Design}

Though the intent of the study was to survey inbound and internal tourists, the political unrest in the Middle East has negatively affected Lebanon's number of arrivals. Therefore, all of the participants in this study were internal travelers. Sample represented those who travel for leisure, learning, and/or working. Overnight stay was not a requirement for inclusion. The study adopted the non-probability quota sampling technique. The technique ensures that various groups of the population are represented in the sample. Group 1 consists of those who live in Beirut. Group 2 consists of those who live in the suburbs and travel on a daily or weekly basis. Group 3 is composed of those who live in remote provinces of the country and travel inter-provinces or to the city.

\section{Instrument}

The instrument was composed of four parts. Items on the first part of the instrument were related to safety of public transport. Respondents rated their responses on a Likert type scale ( $1=$ very frequently, $5=$ never). Items on the second part of the instrument were related to reliability of public transport. Respondents have rated their experiences about the reliability of transport ( 1 = strongly agree, $5=$ strongly disagree). Items on the third part of the instrument were related to travelers' likelihood of being charged a fixed rather than a negotiated price when being transported in Lebanon. Respondents have rated their responses $(1=$ almost always true, $5=$ almost never true). The fourth part of the instrument represented respondents' demographics.

The instrument was pilot tested. Certain items were eliminated from the instrument to achieve greater reliability. The internal consistency of the first three parts of the instrument ranged from 0.67 to 0.81 with an overall consistency of 0.84 . The instrument reliability ranged from 0.69 to 0.82 .

\section{Procedures}

The survey was distributed by a group of MBA students at the Lebanese American University (LAU). Population represented graduate LAU students $(N=100)$ who travel for education and work on a daily basis. None usable responses were eliminated. The number of usable responses is 85 . The study was conducted during spring 2012.

\section{Data Analysis}

The study dependent variables were the three research hypotheses: (1) safety of public transport; (2) reliability of public transportation; and (3) fixed pricing.

Descriptive statistics detailed the demographics and general information related to the problem. Simple linear regression was used in the bivariate analysis to study the relationship between each independent variable and the dependent variable. The last stage included a multivariate analysis via the general linear model to study the reaction of the dependent variable on all significant independent variables. The Statistical Package for Social Sciences (SPSS V20) was used for statistical analysis.

\section{Results}

Accounting to the results, $63 \%$ of the respondents were females and the majority were individuals who travel from different regions of Lebanon and were between the ages of 25 and 29 . More than $80 \%$ of the respondents considered the current public transportation system in Lebanon as a total mess. Concerning the safety of public transport, $95 \%$ of the respondents feel moderately to completely safe on a deluxe bus. 
In respect to the reliability of public transport, $40 \%$ of the respondents considered riding the deluxe bus to be more reliable than driving in bad weather. Similarly, $65 \%$ of the respondents agreed on riding the bus to avoid stress on congested highways. Half of the respondents (50\%) were comfortable in paying a fixed price transport fee for a bus or a cab which provides safety and transport reliability by arriving at the destination on time. Only $10 \%$ of the respondents prefer their current means of transportation which is a rented or personal car as the current public transportation in Lebanon shows neither signs of safety nor order.

Bivariate analysis. Linear regression results indicate that passengers prefer to commute in a deluxe bus because it provides a slight sense of safety than using personal private vehicles $(F=4.621, p>0.03)$ as shown in Table 1. The interest in deluxe bus (dependent variable) and the safety of the bus (independent variable) reveal a significant relationship.

Table 1

Safety

\begin{tabular}{lcrlll}
\hline Model & Sum of squares & df & Mean square & $F$ & Sig. \\
\hline Regression & 1.964 & 1 & 1.964 & 4.621 & $0.034^{\mathrm{a}}$ \\
Residual & 35.283 & 83 & 0.425 & & \\
Total & 37.247 & 84 & & & \\
\hline
\end{tabular}

Note. Dependent variable: interest in deluxe buses in Lebanon. ${ }^{\text {a }}$. Predictors: (Constant), safety.

Regression analysis results indicated that commuting in a deluxe bus provides a stress-free journey and it is far better than driving on congested roads, highway $(F=21.995, p>0.001)$ as shown in Table 2.

Further, if buses were to have a reliable schedule, on-time departure and arrival, reduced commuting time, buses were the most preferred means of transport $(F=8.11, p>0.001)$.

Table 2

Reliability

\begin{tabular}{lcrlll}
\hline Model & Sum of squares & df & Mean square & $F$ & Sig. \\
\hline Regression & 5.718 & 1 & 5.718 & 21.995 & $0.000^{\mathrm{a}}$ \\
Residual & 21.576 & 83 & 0.260 & & \\
Total & 27.294 & 84 & & & \\
\hline
\end{tabular}

Note. Dependent variable: interest in deluxe buses in Lebanon. ${ }^{\text {a }}$. Predictors: (Constant), stress-free.

When asked about the payment method, respondents showed interest in the fixed pricing method which alleviates bargaining over the transportation price with the driver $(F=3.78, p>0.05)$.

Respondents were interested in the monthly payment as it saves transportation cost. Also, there was strong significance between the monthly payment $(F=5.26, p>0.02)$ and the need to make multiple stops along a pre-set corridor, compared to the weekly $(F=4.59, p>0.03)$ and daily payment. The most preferred payment method for those who commute long distances was a monthly payment fee $(F=5.26, p>0.02)$.

Multivariate analysis. The independent variables with a moderate to strong significance with regard to the dependent variable in the multivariate analysis were further tested through a general linear model. The dependent variables are: the interest in using a deluxe hop-on hop-off bus and the area of residency, while the independent variables included are: safety of public transportation, avoiding stress, saving time on the road, reliability of bus during bad weather, controlling heat and air conditioning during travel, and the monthly payment versus the weekly and daily payment. 
The results of the multivariate analysis test showed strong significance for the need to avoid stress and use the bus $(F=7.47, p=0.001)$, the need for a reliable bus $(F=8.16, p=0.01)$ especially for those living far from their work/school, and the need to save time on the road by using the bus $(F=5.10, p=0.012)$. Also, the study shows that those living far from their work/school prefer the monthly payment option $(F=5.15, p>0.01)$ as shown in Table 3.

Table 3

Multivariate Test

\begin{tabular}{|c|c|c|c|c|c|c|}
\hline \multicolumn{7}{|c|}{ Tests of between-subjects effects } \\
\hline Source & Dependent variable & $\begin{array}{l}\text { Type III } \\
\text { Sum of squares }\end{array}$ & df & $\begin{array}{l}\text { Mean } \\
\text { square }\end{array}$ & $F$ & Sig. \\
\hline \multirow{2}{*}{ Corrected model } & $\begin{array}{l}\text { Interest in deluxe buses } \\
\text { in Lebanon }\end{array}$ & $8.823^{\mathrm{a}}$ & 20 & 0.441 & 2.144 & 0.13 \\
\hline & Q10 interested & $0.961^{\mathrm{b}}$ & 20 & 0.048 & 0.983 & 0.493 \\
\hline \multirow[t]{2}{*}{ Intercept } & $\begin{array}{l}\text { Interest in deluxe buses } \\
\text { in Lebanon }\end{array}$ & 38.770 & 1 & 38.770 & 188.388 & 0.000 \\
\hline & Q10 interested & 19.864 & 1 & 19.864 & 406.186 & 0.000 \\
\hline \multirow[t]{2}{*}{ Q119LessStress } & $\begin{array}{l}\text { Interest in deluxe buses } \\
\text { in Lebanon }\end{array}$ & 3.076 & 2 & 1.538 & 7.474 & 0.00 \\
\hline & Q10 interested & 0.012 & 2 & 0.006 & 0.126 & 0.883 \\
\hline \multirow{2}{*}{ Q118MoreReliable } & Q10 interested & 0.206 & 1 & 0.206 & 8.164 & 0.00 \\
\hline & Location 2 & 0.666 & 1 & 0.666 & 2.356 & 0.13 \\
\hline \multirow{2}{*}{$\begin{array}{l}\text { Location } 3 \\
\text { Q12Price1month }\end{array}$} & $\begin{array}{l}\text { Interest in deluxe buses } \\
\text { in Lebanon }\end{array}$ & 3.101 & 2 & 1.551 & 7.535 & 0.00 \\
\hline & Q10 interested & 0.074 & 2 & 0.037 & 0.761 & 0.47 \\
\hline \multirow{2}{*}{$\begin{array}{l}\text { Q119LessStress } \\
\text { Q12Price1month }\end{array}$} & $\begin{array}{l}\text { Interest in deluxe buses } \\
\text { in Lebanon }\end{array}$ & 0.128 & 1 & 0.128 & 0.620 & 0.43 \\
\hline & Q10 interested & 0.012 & 1 & 0.012 & 0.243 & 0.62 \\
\hline \multirow{2}{*}{$\begin{array}{l}\text { Q113ChangeIfSaves } \\
\text { Time }\end{array}$} & Q10 interested & 0.257 & 2 & 0.129 & 5.104 & 0.01 \\
\hline & Location 2 & 0.651 & 2 & 0.325 & 1.151 & 0.32 \\
\hline \multirow{2}{*}{$\begin{array}{l}\text { Location3 } \\
\text { Q119LessStress } \\
\text { Q12Price1month }\end{array}$} & $\begin{array}{l}\text { Interest in deluxe buses } \\
\text { in Lebanon }\end{array}$ & 2.122 & 2 & 1.061 & 5.156 & 0.00 \\
\hline & Q10 interested & 0.161 & 2 & 0.080 & 1.645 & 0.20 \\
\hline \multirow[t]{2}{*}{ Error } & $\begin{array}{l}\text { Interest in deluxe buses } \\
\text { in Lebanon }\end{array}$ & 11.936 & 58 & 0.206 & & \\
\hline & Q10 interested & 2.836 & 58 & 0.049 & & \\
\hline \multirow[t]{2}{*}{ Total } & $\begin{array}{l}\text { Interest in deluxe buses } \\
\text { in Lebanon }\end{array}$ & 135.000 & 79 & & & \\
\hline & Q10 interested & 91.000 & 79 & & & \\
\hline \multirow[t]{2}{*}{ Corrected total } & $\begin{array}{l}\text { Interest in deluxe buses } \\
\text { in Lebanon }\end{array}$ & 20.759 & 78 & & & \\
\hline & Q10 interested & 3.797 & 78 & & & \\
\hline
\end{tabular}

Note. ${ }^{\mathrm{a}} . R$-squared $=0.425$ (adjusted $R$-squared $\left.=0.227\right) .{ }^{\mathrm{b}}$. $R$-squared $=0.253$ (adjusted $R$-squared $\left.=-0.004\right)$.

However, the test revealed no significant relationship between the safety of the public transportation and the use of the hop-on hop-off deluxe bus meaning that the respondents do not trust that any kind of transportation can ensure safety as the road safety in Lebanon is hazardous and not driver friendly. Lebanese people need to gain trust in the public transportation in Lebanon, and one way of improving this fact is by introducing safe hop-on hop-off deluxe buses that will challenge the perception of public transportation in Lebanon. 


\section{Discussion}

The results of running the multivariate test to the three more or less significant independent variables have revealed the following:

(1) Safety of public transportation has no relationship with the increasing use of public transport. Respondents argued that transport safety is compromised throughout the country. The hypothesis that safety of public transportation will increase the use of the deluxe buses is not supported. However, the hop-on hop-off deluxe bus service which the study is proposing aims to improve the quality of public transportation in Lebanon and to build trust in its safety;

(2) Reliability of public transportation in Lebanon is positively related to the use of public transportation, and in turn, the study proposed deluxe hop-on hop-off buses. Reliable buses are very important for the citizens as well as for the tourists. The study proposes the development of bus stations all over Lebanon, use the right lane only to avoid accidents and bad driving attitudes, and work hand in hand with the government, municipalities, and other private organizations interested in improving road safety. These will aim to enhance our routes and the multiple stop function without challenging the traffic;

(3) Fixed pricing is positively related to the use of public transportation and thus the use of our deluxe bus. In fact, fixed pricing is crucial to ensure professionalism, avoid bargain and rip-offs, and save time for travelers by providing them with the information needed prior to the trip.

\section{Limitation and Conclusion}

The study was carried out under a cross-sectional time frame knowing that it was initiated as part of an MBA course. This was the main limitation for the study. The state of the transport system in Lebanon is critical; citizens do not feel safe on any public or private personal transport. This has certainly created bias affecting our first hypothesis.

Knowing that Lebanon is facing low seasons of tourism, it was difficult to find tourists to survey. Consequently, our sample represented Lebanese people engaging in internal travel. However, the study could be broadened to include the opinion of tourists from other countries for more accurate answers.

\section{References}

Azakir, M. (2014). MP: Public transportation a high priority. Retrieved from http://www.dailystar.com.lb/News/Lebanon-News/2014/Jul-15/263949-mp-public-transportation-a-high-priority.ashx\#ixzz3 GftYioZi

BEFORWARD. (2014). Cars per capita in Africa - Which country has the most cars on the road? Retrieved from http://blog.beforward.jp/regional-topics/africa/cars-capita-africa-country-cars-road.html

Brida, J. G., \& Risso, W. A. (2010). Tourism as a determinant of long-run economic growth. Journal of Policy Research in Tourism, Leisure and Events, 2(1), 14-28. doi: 10.1080/19407960903542276

Bureau of Diplomatic Security. (2014). Lebanon 2014 crime and safety report. Retrieved from https://www.osac.gov/Pages/ContentReportDetails.aspx?cid=15665

Choueiri, E. M., Choueiri, G. M., \& Choueiri, B. M. (2012). An overview of land transport in Lebanon, with special emphasis on traffic safety. Advances in Transportation Studies. Retrieved from http://search.proquest.com/

Downward, P., \& Lumsdon, L. (2004). Tourism transport and visitor spending: A study in the North York Moors National Park, UK. Journal of Travel Research, 42(4), 415-420.

International Road Federation. (2015). World road statistics 2015. Geneva: IRF. 
Khraiche, D. (2011). Lebanon needs an efficient public transport: Berro. The Daily Star. Retrieved from http://www.dailystar.com.lb/Business/Lebanon/2011/May-24/139447-lebanon-needs-an-efficient-public-transport-berro.ashx \#axzz3HKs9eSoR

Li, Y., \& Lo, L. B. R. (2005). Opportunities and constraints of heritage tourism in Hong Kong's changing cultural landscape. Tourism and Hospitality Reasearch, 5(4), 322-345.

Malhado, A. C., \& Rothfuss, R. (2013). Transporting 2014 FIFA World Cup to sustainability: Exploring residents' and tourists’ attitudes and behaviours. Journal of Policy Research in Tourism, Leisure and Events, 5(3), 252-269. doi: 10.1080/19407963.2013.801159

Mammadov, R. (2012). The importance of transportation in tourism sector. Tourism and Investment Opportunities, 381-386.

Manohar, B., \& Kumar, V. (2012). Green transportation - Public sector transport system. Retrieved from http://search.proquest.com/docview/1317617160/1071FD349340449APQ/1?accountid=27870

Obeid, M., \& Diab, D. (2012). How to reduce traffic in Beirut. The Daily Star. Retrieved from http://www.georgessassine.com/how-to-reduce-traffic-in-beirut/

Otego, D. (2008). Tourism and transport. Toot Publishers. In Kelvin. Transport and Tourism. Retrieved from http://anonnaworld.blogspot.com/2013/01/critical-aspects-of-tourism-transport.html

Popuri, Y., Proussaloglou, K., Ayvalik, C., Koppelman, F., \& Lee, A. (2011). Importance of traveler attitudes in the choice of public transportation to work: Findings from the Regional Transportation Authority Attitudinal Survey. Transportation, 38(4), 643-661.

Sorupia, E. (2005). Rethinking the role of transportation in tourism. Proceedings of the Eastern Asia Society for Transportation Studies, Vol. 5, pp. 1767-1777, Tokyo.

The World Bank. (2014). Transport: Sector results profile. Retrieved from http://www.worldbank.org/en/results/2013/04/14/transport-results-profile

Truong, V. D. (2013). Tourism policy development in Vietnam: A pro-poor perspective. Journal of Policy Research in Tourism, Leisure and Events, 5(1), 28-45. doi: 10.1080/19407963.2012.760224

Vincent, M. (2008). Measurement valuation of public transport reliability. Land Transport New Zealand Research Report 339.

Whiting, R. (2013). On the road in Lebanon, safety is secondary. Alakhbar. Retrieved from http://english.al-akhbar.com/node/14681

World Health Organization. (2004). World report on world traffic injury prevention.

Wu, Y., Xu, H., \& Eaglen, A. (2011). Tourism-dependent development: The case of Lijiang, Yunnan province, China. Journal of Policy Research in Tourism, Leisure and Events, 3(1), 63-86. doi: 10.1080/19407963.2011.539382 